Kari Iren Spernes* and Rose Ruto-Korir

\title{
Medium of instruction in school: The indigenous language, the national language or the official language? A case study from multilingual deep rural Kenya
}

https://doi.org/10.1515/jall-2018-0002

\begin{abstract}
The connection between multilingualism and the school curriculum continues to engender debates on language preferences because of the potential to influence the amount of learning among learners. To understand language preferences among multilingual learners and their implications for the selection of the medium of instruction (MoI) in a multilingual country, data were collected through questionnaires and interviews among learners, teachers and head teachers in deep, rural Kenyan primary schools. These schools are located away from urban centres, with little or no basic infrastructure, hence the concept of "deep ruralness”. The participants were purposively sampled from among learners, teachers and head teachers to examine how learners' affiliations with multilingualism could explain the preferred MoI, and the ways through which schools implement the use of an MoI in the curriculum. The findings show that Kiswahili and English were used as the MoI, even when the curriculum recommended indigenous languages and English. Moreover, learners' multilingual affiliations and their spontaneous languages were their indigenous languages and Kiswahili. Based on these findings, we claim that the indigenous language, Kiswahili and English should be used as the languages of instruction in Kenyan schools.
\end{abstract}

Keywords: curriculum, indigenous language, medium of instruction, multilingualism, rural Kenya

\section{Medium of instruction in multilingual Africa}

As in other research, the medium of instruction (MoI) preference in this paper is conceptualised to refer to the language that teachers prefer to use when communicating the curriculum. MoI selection has implications beyond its use in the curriculum, as it is linked to political, economic and social identity nuances.

*Corresponding author: Kari Iren Spernes, Østfold University College, Østfold, Norway, E-mail: kari.i.spernes@hiof.no

Rose Ruto-Korir, Moi University, Eldoret, Kenya, E-mail: korircheptoo@gmail.com 
More importantly, the MoI supports mastery of the curriculum content because it positions learners to succeed differently as "a key factor which can either facilitate and optimise access to the content of the curriculum or block learning, preventing both access and equity" (Heugh et al. 2007: 11).

In this study, language preferences were investigated to understand their implications on the MoI in rural schools in Kenya because this perspective is rarely considered. Clearly, the MoI is important, and it has generated an emotive debate in schools in Africa "and (is) at the root of understanding inequalities in Africa's education systems” (Altinyelken et al. 2014: 90). Assessed from a postcolonial paradigm, the widespread post-colonial influences before independence introduced competition and incongruence between the familiar African language, which served a generative cultural and education function. However, research has indicated that post-colonial languages are often used as the MoI in African schools and that there is a lack of congruence between education and African language and culture (Brock-Utne 1997; Brock-Utne 2007; Brock-Utne and Holmarsdottir 2004; Opoku-Amankwa 2009; Shiza 2005; Spernes 2012; Trudell 2005). When bilingualism is considered within MoI debates, studies on bilingual education in both Africa (Brock-Utne and Holmarsdottir 2004; Heugh 2009; Skutnabb-Kangas 2009) and elsewhere (Cummins 2007; Krashen 1985; Thomas and Collier 1997) have shown a connection between the MoI and bilingual learners' lack of learning outcomes and indicate the importance of the mother tongue (MT) as an MoI in schools.

MoIs have attracted special interest in Kenya due to the curriculum reform in 2017, which still emphasises the mother tongue (MT) as the MoI at the lower primary school levels. Furthermore, a report by one non-governmental organisation (Uwezo 2016) painted a bleak picture of the continued poor learning outcomes at the primary levels despite considerable government expenses. This not only raises questions regarding the amount of learning that takes place, but also generates further layered debates regarding whether it is the learners' preferences of an MoI that could provide partial answers to the questions of how much learning takes place at the primary schools. At the lower level, such debates are critical because they influence success in subsequent levels of education. More so, in a country like Kenya, which currently has 44 acknowledged ethnic communities, each with their respective indigenous languages, questions related to the MoI become more complex and need to be assessed within homogeneously ethnic-located rural schools. In addition to the indigenous languages, also conceptualised here as the MTs, Kiswahili ${ }^{1}$ is

1 Kiswahili is the name of the language, but in most books written during colonialism, the word 'Swahili' is used to refer to the language (Puja 2003). 
the national language, and Kiswahili and English are both official languages of Kenya. People in urban Kenya primarily use Kiswahili and English, but twothirds of the Kenyan population, mainly in rural areas, use an indigenous language as their MT in addition to Kiswahili (Githiora 2008). This article presents data from an ethnographical case study in a deep, rural Kenyan district called Nandi and provides some of the preliminary results of the study. Nandi is used synonymously to refer to the geographic context or locale, the inhabitants' culture and their indigenous language. In Kenya's multilingual society, it was interesting to examine the ways in which learners understand and use their multiple languages at home and in school. The aim of this study was to examine which language was most preferred as the MoI by multilingual learners in deep rural Kenya.

Furthermore, a description of the ways in which the MT, Kiswahili and English are made visible in the Kenyan curriculum is provided. Section 3 discusses Vygotsky's theory of spontaneous and academic concepts and the importance of the ways in which the MT facilitates learning in other foreign languages. An overview related to multilingualism and educational languages in Africa is presented, and the research questions demonstrate the contributions to existing research. In Section 5, the method and the data analysis are described. In the discussion, the findings in the light of previous research are problematized, and the discussion of Vygotsky's concepts is overlaid on the findings. Finally, the conclusions are presented, and a successive multilingual model in which the indigenous language, Kiswahili and English become the MoI in education is proposed.

\section{Multilingualism in the Kenyan curricula}

Since the first post-independence Education Commission in Kenya, the Ominde Commission in1964, the curriculum framework has undermined indigenous languages and Kiswahili and has prioritised English. The next commission, the Gachati Report of 1976, emphasised education for national unity and cultural aspirations; however, English was still prioritised at the expense of indigenous languages and Kiswahili. The Mackay Report of 1981 continued to emphasise English as the MoI, with Kiswahili being one of the compulsory subjects (Githiora 2008). In today's curriculum, since 2002, the MT has become a subject of study as well as the MoI in lower primary education. The MT as the MoI is presented in the introduction to English subjects: 
In standard one to three, it [English] is taught as a subject, while mother tongue is used as a medium of instruction. In standard four to eight it is taught as a subject and used as the medium of instruction in other subjects (Kenya Institute of Education 2002: 2).

The syllabus presented in 2002 does not provide a definition for MT, but in this paper, it is conceptualised as the indigenous languages within a typically rural homogenous community that shares a culture and a common language. The 2002 syllabus does not discuss the MoI at lower primary levels for one-third of learners who do not have an indigenous language as their MT (cf. Githiora 2008). The MT was proposed as a subject of study and MoI for these reasons: it supports (a) language and thought, (b) cultural heritage, (c) home language; and d) it is a foundation for self-confidence and (e) a tool for learning (Kenya Institute of Education 2002: 150).

In Kenya, the syllabus is written in English, with the exception of the chapter on the Kiswahili subject, which is written in Kiswahili. Kiswahili is not mentioned as an MoI, but it is a subject of study from standards one to eight (equivalent of the primary cycle years). The curriculum connects the significance of Kiswahili as a subject to three proposed values: the advancement of the Kenyan economy, the propagation of culture and the enhancement of communication and relationships among people. The syllabus recommends English as the MoI in upper primary education.

\section{Vygotsky's theory of concepts and language learning}

To understand learners' competences in different languages, Vygotsky's theory published in Thought and Language (2012 [1934]) was used. Specifically, the theory's elements regarding the differences and the relations between spontaneous and academic concepts and Vygotsky's beliefs for developing an indigenous language and learning a foreign language were most valuable. Vygotsky's theoretical concept, which is related to the zone of proximal development, implies that the language that learners most often use is scaffolded, which can assist in the analysis of the preferred language of instruction in relation to the selection of an MoI in this study. In the following two sub-sections, spontaneous and academic concepts and the connections between indigenous and foreign languages as two broad foundations used to overlay the theoretical understanding of this study are explored. 


\subsection{Spontaneous and academic concepts}

According to Vygotsky (2012), spontaneous concepts are developed in a child's mind and emerge from the child's daily experiences and reflections on these experiences. Spontaneous concepts are concepts that are adequate for the child's daily life (Kozulin 2012), and the child assigns meanings to the concepts through experiences. The development of spontaneous concepts does not follow systematic processes, but the concepts develop based on the child's reflections on the experiences toward generalisations. Academic concepts, on the other hand, are learned in a structured and specialised manner. The acquisition of academic concepts occurs based on deliberate instructional activities, such as in a classroom. Vygotsky therefore referred to spontaneous concepts as developed through daily experiences and academic concepts as learned in school. While spontaneous concepts are situational and practical, academic concepts are conscious and deliberate.

Although the emergence of the two groups of concepts is different, according to Vygotsky (2012), there are connections between them. Learners do not come to school as "empty boxes," rather they have experiences from their interactions in daily life to which they generalise other new concepts that they encounter beyond "academic" concepts. The academic concepts develop depending on the existing level of a child's general ability to comprehend concepts. Based on Vygotsky's theorising, experiences acquired through the MT become the raw materials for developing "academic" concepts. Therefore, Vygotsky's theory suggests that the child comes to school with a background through the zone of proximal development that supports the child in transitioning into learning through emerging interactions with the teacher, who scaffolds what the child already knows. This zone is "a psychological 'space' where learners' experientially rich spontaneous concepts meet the teacher's systematically organized academic concepts" (Kozulin 2012: xviii). Cognitive processes cannot be developed in the absence of interaction, but when learners interact with the teacher, the learners will reach a higher cognitive level.

\subsection{Connection between the indigenous language and a foreign language}

To obtain a deeper understanding of spontaneous and academic concepts, Vygotsky (2012) compared the difference between developing an indigenous language and learning a foreign language and claimed that they are two 
different processes. Vygotsky understood the development of an indigenous language as a spontaneous process, while learning a foreign language as a non-spontaneous, or academic, process. The indigenous language is developed by constructing concepts through experiences, while the foreign language is developed through systematic instruction based on previously known concepts. According to Vygotsky (2012), the indigenous language is also further improved by learning a foreign language because the acquired competence in the new language makes the learner more aware of how to use words to express thoughts.

Although Vygotsky's concepts might be limiting, or even contestable, they provided this research with a basic theoretical framework that rationally anchored the arguments to scholarship, especially in the absence of another concise social cultural theory.

\section{Research overview and the research question}

Researchers, educationists, indigenous activists and international organisations, such as UNESCO, have been advocating for the use of MTs in schools (Trudell 2007). However, policy makers and educators at the community level are still concerned about the "potential political and educational repercussions of doing so", arguing that the use of MTs could exclude learners in curriculum mastery, as its benefits are less valued, leading to hesitation in introducing an MT as an MoI in schools (Abdulaziz 2003, citied in Trudell 2007: 553). Studies from Kenya and other African countries have indicated that parents are not aware of the importance of MTs and that they prefer English as the MoI in schools (e.g. Altinyelken et al. 2014; Brock-Utne 1997; Spernes 2011). Parents claim that their children's future employment opportunities and social status engender their preference. The parents represent a section of the population that prioritizes English, which may explain why some learners may even be punished if they speak indigenous languages in schools (Spernes 2012; Trudell 2005). There is a strong link between indigenous languages and social identity (Gandolfo 2009). Languages symbolise what people want to express, and a versatility in languages makes it easier to communicate (Omoniyi and White 2006). The MT is also used to express positive feelings and "to express feelings of anger and excitement, to curse, to insult, to swear, to complain and to threaten” (Lunga 2004: 316).

One study done in Kenya examined teaching practices at the classroom level and related the practices to learners' scores on a curriculum-based test (Ngware 
et al. 2014). All teaching was performed in English, which was not the MT of many learners. One of the findings was that pupils who spoke English outside school scored significantly higher than those who did not. Ngware et al. (2014) claimed that there are positive effects on learning achievements when learners speak the MoI at home and with friends.

Brock-Utne and Holmarsdottir (2004) compared language politics and language practices in schools in Tanzania and South Africa. In both countries, most learners struggled to learn academic content because the MoI in school was not their MT. Brock-Utne and Holmarsdottir claim that poor grades, repetition and drop-out rates are language problems. Another study from Tanzania showed significant differences in learners' activities when learners were taught in different languages: learners taught in their MT were active, while learners taught in English were passive (Brock-Utne 2007).

Altinyelken et al. (2014) explored teachers' challenges regarding the implementation of the indigenous language as the MoI in Uganda in 2007. Teachers in rural areas showed minimal enthusiasm for the MT as the MoI, even if most of them reported higher activity in the classroom when using the MT. The reason was that the teachers identified problems when the learners began upper primary school where the MoI was English. According to Altinyelken et al. (2014), other African countries, including Kenya, have argued that strengthening the MT may cause divisions and class distinctions.

An example of a successful successive bilingual model is PROPELCA (Operational Research Project for the Teaching of Cameroonian Languages) in Cameroon. When learners begin class one, approximately 80-90 percent of class time is in the MT, and the proportion decreases each year until 80-90 per cent of class time in class four is conducted in English. In a comparative study between English-only classes and bilingual classes, Trudell (2005) found that bilingual instruction affected positively the quality of classroom communication when two-way communication was the norm. The score in English was also higher in the PROPELCA classes.

The MT is synonymous with the learners' indigenous language, and the studies highlighted the MT as the preferred MoI in schools. In this study, as in previous studies, the learners were multilingual. In addition to examining learners' affiliations with multilingualism to obtain information regarding the preferred MoI, the ways through which schools implement the use of an MoI in the curriculum was of interest. Thus, the following research questions were developed:

- Could schools' implementation of the curriculum and multilingual learners' affiliations with their different languages indicate which language may be preferred as the MoI in education? 
- How is the curriculum's emphasis on English, Kiswahili and the MT addressed in the schools?

- Where and with whom do the multilingual learners use their three languages?

- How do learners understand their own multilingual competence and the value of their languages?

\section{Methodology}

An ethnographic case study is an exploration of a bounded system, and languages and communication styles are central to this type of case study (Creswell 2012). These data were collected in a bounded period, which was February 2017, in a bounded area, where the local people spoke the indigenous language, Nandi, with potential to speak Kiswahili, as the national language. A case study focuses on activities involving individuals (Creswell 2012). For this article, the informants were learners, teachers and head teachers in three schools in deep, rural area: Nandi of Kenya. The triangulation of sources provided different points of view and enhanced the validity of the findings (Stake 1995; Yin 2003). The data were collected while the learners were in their first term of standard eight, when they had had experiences with different languages from when they enrolled in preprimary school for three years, and for at least seven years in primary school. ${ }^{2}$ The informants in this study included 64 learners, 31 girls and 33 boys; 15 teachers, four females and 11 males; and three head teachers, all males.

The study site was a deep, rural area in Nandi County, Western Kenya region. The catchment area of the schools was mainly occupied by maize farmers, living in houses without basic infrastructures. The nearest urban centre from the participating schools was more than 50 kilometres away. This is the rationale for the conceptualisation of a deeply rural setting.

The primary data used in this paper were obtained from open-ended questionnaires. All 64 questionnaires from among learners, 15 from among teachers and three from among head-teachers were self-administered and analysed. The questions to the learners focused on where and with whom they spoke the three languages, Nandi, Kiswahili and English, and their opinions of their level of competence in these languages. There were also closed-ended questions for which they rated their opinions about how well they understood, spoke, read and wrote the three languages using a scale from zero to five (where zero was no

2 The learners may have had more than eight years' experience in primary school. If learners do not pass the exams, they must repeat the class. 
competence and five was very good competence). The questionnaires were completed in class, after instructions on how to complete them were given in all languages. The head teachers also told the learners that they could speak Nandi with the researchers. (This was necessary because our understanding was that the learners were not allowed to speak Nandi in school.) In one school, the 21 learners in one class were also asked to identify the language(s) they used when they sent short text messages (SMSs) to their friends. This question explored the language(s) between friends.

The teachers completed a questionnaire with open-ended questions about the learners' competence in and use of the three languages. They were also asked to rate the learners' abilities to express their feelings in the three languages on a scale from zero to five (where zero was no possibility and five was very good possibility). This question was asked because feelings are often expressed through the spontaneous language (Vygotsky 2012). The head teachers completed an openended questionnaire about the languages used and taught in school, while one of the head teachers was interviewed for in-depth meaning-making.

The teachers and head teachers were informed that their participation was voluntary, and all participated. A multilingual research assistant who spoke the same languages as the learners participated in the data collection and transcribed and translated the data. One of the researchers was multilingual and spoke the three languages. This researcher ensured accurate translations, and the researcher's knowledge of the Nandi language and culture was valuable at all stages of the project, including preparation (both theoretical and practical), fieldwork and analyses. This pre-knowledge enhanced the validity and reliability of the findings (cf. Miles and Huberman 1994; Yin 2003). During the analysis process, the data were examined, and an overall understanding was developed (cf. Creswell 2012) before themes were identified based on the data, the research questions, prior research and the theory. To determine the themes, frequently mentioned concepts or topics and similarities and differences between the informants' answers were evaluated (cf. Ryan and Bernard 2003). Where it is necessary to visualise the data, graphs and tables are provided. The percentage is approximate.

\section{Perceived learners' competencies in languages used in context}

This section presents the data used for the research questions. In addition to the analyses of the head teachers' answers to the questionnaire and one head teacher's interview, analyses of the teachers' opinions about the learners' 
competences in Nandi, Kiswahili and English as well as their perceptions of the learners' use of their three languages in the light of the curriculum are presented. In Section 6.2, the learners' perspectives of their multilingualism and their opinions about their competences are discussed. In Section 6.3, a summary of the head teachers', teachers' and learners' perceptions about language use is provided.

\subsection{Languages in school, the head teachers and the teachers' perspectives}

In Section 6.1.1, the head teachers' perspectives of the curriculum, MT and MoI are discussed, and in 6.1.2, the teachers' perspectives of the learners' multilingualism abilities are described.

\subsubsection{Perspectives of the head teachers on curriculum, MT and Mol}

Based on the data regarding the head teachers' perspectives, two themes emerged. The first is the disconnect between the curriculum policy recommendations and the practices in schools. The second is the punishment of learners in upper primary who used their MT in school, which was not allowed.

\subsubsection{The disconnect between the curriculum and practice in schools}

All the head teachers stated that they were from the Nandi culture and that Nandi was their MT. They also stated that most of the learners and the teachers at the school were Nandi. As mentioned, the Kenyan syllabus from 2002 highlights the MT in lower primary school as a subject of study; however, Nandi was not a subject of study in any of the schools, even if the head teachers said the curriculum mandated Nandi. The head teachers did not explain the reason for this, so the question was raised when one of the head teachers was interviewed. He stated that he did not know the other head teachers' reasons because they did not discuss them. As an explanation for why his school did not include Nandi in school, he said he did not know any schools that included Nandi as a subject. He said, "People don't want the tribe language. Here in my school, the parents don't want Nandi”. His opinion was the same as the parents' opinion, "Kiswahili and English are more important for the learners". This is the same explanation given in previous research (e.g., Altinyelken et al. 2014; Brock-Utne 1997; Spernes 2011). 
According to the Kenyan syllabus of 2002, the MT should be the MoI in lower primary education and English in upper primary education; however, the schools do not follow this recommendation. Table 1 shows the MoI in the three schools studied.

Table 1: Mol in three deeply rural schools.

\begin{tabular}{llllll}
\hline School & $\begin{array}{l}\text { Preschool } \\
\text { (Baby/Middle) }\end{array}$ & Top-Class & $\begin{array}{l}\text { Lower } \\
\text { Primary-1 \& 2 }\end{array}$ & $\begin{array}{l}\text { Lower } \\
\text { Primary 3 }\end{array}$ & $\begin{array}{l}\text { Upper Primary } \\
\text { (4-8) }\end{array}$ \\
\hline School 1 & $\begin{array}{l}\text { Nandi \& } \\
\text { Kiswahili }\end{array}$ & Nandi \& Kiswahili & Kiswahili & Kiswahili & $\begin{array}{l}\text { Kiswahili \& } \\
\text { English }\end{array}$ \\
School 2 & $\begin{array}{l}\text { Nandi \& } \\
\text { Kiswahili }\end{array}$ & Kiswahili & $\begin{array}{l}\text { Kiswahili \& } \\
\text { English }\end{array}$ & $\begin{array}{l}\text { Kiswahili \& } \\
\text { English }\end{array}$ \\
School 33 & $\begin{array}{l}\text { English } \\
\end{array}$ & Nandi, Kiswahili \& & Nandi, \\
& & Kiswahili \& & Kiswahili \& & Kiswahili \& \\
& & & English & English \\
\hline
\end{tabular}

All the schools have different practices related to the MoI, and none followed the instructions from the syllabus. Nandi was only the MoI in one school for the first two years of primary school, and Kiswahili, which is not mentioned as an MoI in the syllabus, was the MoI in all classes except upper primary classes in one school. These findings are not unique to these three schools. Muthwii (2004) also found that schools might use indigenous languages, Kiswahili or English as the MoI in Kenyan schools.

\subsubsection{Shaming of learners who use Nandi}

The head teacher explained in the interview that learners were punished if they used Nandi in upper primary classes (cf. Spernes 2012; Trudell 2005): "The teachers give the disk to pupils who speak Nandi when they are not allowed". He said that "a disk" was a piece of wood hanging from a rope around a learner's neck. When a teacher hears a learner using Nandi in class or in the schoolyard, the teacher hangs the disk around his/her neck. The learner with the disk gives the disk to the next learner heard speaking Nandi, and so on. Ultimately, all learners who contravene the language rule meet in the office where they are advised, and they receive manual work for one or two hours, which could include practical work, such as cleaning the classroom or the schoolyard. The interviewee stated that, "before 2013, they were corporally punished. This is not allowed today, but sometimes we do. We can also contact parents". Corporal punishment was outlawed in schools in 2013. 
The head teacher noted that shaming through the disk has been the practice in Kenyan schools since the colonial period. During the interview, he telephoned two other head teachers to ask about their punishment practices. In one of the schools, the disk was used in classes four to eight, while in another, in classes six to eight.

\subsubsection{The teachers' perceptions of learners' language competences and preferences}

The teachers gave their perceptions of the learners' competences in their three languages. The learners' competences were scaled from zero to five with the latter having the highest competence.

As Figure 1 shows, all teachers indicated that Kiswahili was the language the learners understood, spoke and wrote best. For reading proficiency, seven teachers identified Kiswahili, while eight identified English. The teachers were also asked to scale an average learner's ability to express his/her feelings in the three languages. As mentioned, this question was asked because feelings are often expressed through the spontaneous language (cf. Vygotsky 2012).

All but one teacher said the learners had good or very good abilities to express their feelings in Nandi, and nine said the same in Kiswahili. For English, most of the teachers answered "fair". Four teachers said Nandi was the language the learners would prefer to use to express their feelings, eight teachers said Kiswahili and three said English. The themes that emerged from the data collected from the teachers are shown in Table 2.

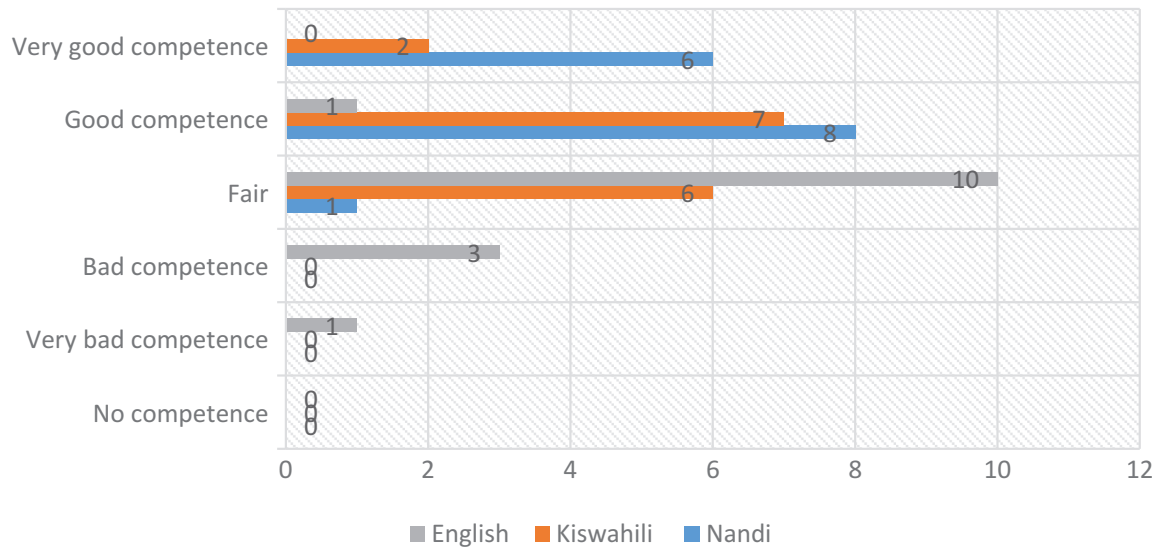

Figure 1: The teachers' perceptions of learners' multilingual competence in expressing feelings. 
Table 2: The teachers' perceptions of the reasons the learners preferred a specific language.

\begin{tabular}{|c|c|c|c|c|}
\hline Language & School 1 & School 2 & School 3 & Themes \\
\hline Nandi & $\begin{array}{l}\text { - They are proud, and } \\
\text { they prefer this } \\
\text { language because it } \\
\text { is widely used } \\
\text { - They use Nandi for } \\
\text { clarity and } \\
\text { understanding }\end{array}$ & $\begin{array}{l}\text { - They use Nandi } \\
\text { because it is } \\
\text { their MT } \\
\text { - They have } \\
\text { a better } \\
\text { understanding } \\
\text { of that language }\end{array}$ & & $\begin{array}{l}\text { - Source of pride } \\
\text { - Language is } \\
\text { easy to } \\
\text { understand }\end{array}$ \\
\hline Kiswahili & $\begin{array}{l}\text { - Because everybody } \\
\text { uses Kiswahili and } \\
\text { most of the words } \\
\text { are clear and } \\
\text { simple and } \\
\text { therefore } \\
\text { understood by } \\
\text { everybody } \\
\text { - Because this } \\
\text { is a language } \\
\text { spoken more often }\end{array}$ & $\begin{array}{l}\text { - Because } \\
\text { Kiswahili is a } \\
\text { commonly used } \\
\text { language in } \\
\text { school } \\
\text { - Because they } \\
\text { are able to } \\
\text { explain } \\
\text { themselves } \\
\text { comfortably }\end{array}$ & $\begin{array}{l}\text { - Because it is a } \\
\text { well-understood } \\
\text { language; it is } \\
\text { commonly used } \\
\text { in the catchment } \\
\text { area } \\
\text { - Because } \\
\text { Kiswahili is used } \\
\text { in the catchment } \\
\text { area } \\
\text { - It is commonly } \\
\text { used in the } \\
\text { village }\end{array}$ & $\begin{array}{l}\text { - Frequent use of } \\
\text { language in } \\
\text { the catchment } \\
\text { and spoken } \\
\text { around the } \\
\text { learners } \\
\text { - Simplicity due } \\
\text { to language } \\
\text { structure } \\
\text { - Learners' } \\
\text { confidence in } \\
\text { using it }\end{array}$ \\
\hline English & & $\begin{array}{l}\text { - It is a language } \\
\text { allowed in } \\
\text { school } \\
\text { - English is the } \\
\text { official language } \\
\text { - It is the national } \\
\text { language } \\
\text { learned in } \\
\text { school }\end{array}$ & & $\begin{array}{l}\text { - Official } \\
\text { language } \\
\text { - Language } \\
\text { accessed } \\
\text { through } \\
\text { learning in } \\
\text { school }\end{array}$ \\
\hline
\end{tabular}

The teachers' primary argumentation for the learners' choices to express feelings in Nandi and Kiswahili was the learners' competences and the prevalence. The argument for English was that it was the school language and the official language.

\subsection{The learners' perceptions of their multilingualism}

The learners answered questions related to being multilingual. First, in Section 6.2.1, the learners' perspectives related to where and with whom they speak and 
prefer to speak Nandi, Kiswahili and English and the reasons they need to be competent in these languages are discussed. In Section 6.2.2, the learners' opinions of their competence in the three languages are presented.

\subsubsection{The learners' perceptions of the use of the three languages}

In this section, the learners' perspectives related to each of the languages, Nandi, Kiswahili and English, are discussed.

\subsubsection{Nandi language}

Almost all the learners, 58 (90\%) out of 64, said that Nandi was their MT when it was explained that the MT is the language they developed from birth. Three learners (5\%) identified both Nandi and another indigenous language as their MT, while only one learner recognized Kiswahili as the MT. After reviewing the class list from the head teachers, it was found that all the learners had Nandi names. Therefore, it was somewhat surprising that one learner categorised her MT as Kiswahili, in the research area where almost all people were recognised as Nandi, spoke the Nandi language and belonged to the Nandi culture (cf. Tchindjang et al. 2008).

The learners said that they learned Nandi at home, and all except three learners (5\%) said that they learned Nandi when they were toddlers or small children. The other three learners said they learned Nandi in pre-primary school. Almost all the learners (97\%) said they spoke Nandi with their parents; some also reported grandparents, older people and people in the village. 14 learners (22\%) mentioned friends in connection with family. One of the learners said she spoke Nandi with her teachers, which is difficult to believe due to the punishments. One explanation may be that the learner spoke with teachers outside of school. All the learners except one said they preferred to speak Nandi at home, and the other learner said at home and at school. Again, it should be emphasised that the learners in standard eight were not allowed to speak Nandi in school, but it may be that the learner who said she spoke Nandi in school spoke Nandi with her friends when teachers or learners with a disk did not hear.

If the learners had difficulties understanding the Nandi language, 33 (52\%) reported that they mainly asked a member of the family, while 25 (39\%) said that they asked someone or tried to find out without specifying from whom. Four learners $(6 \%)$ sought support from friends. Contrary to the expectation and practice of shaming, two learners said they could ask the teacher, a response that somewhat raises credibility issues in a context where shaming would deter learners from seeking support through Nandi when they faced learning 
challenges. Most learners, i.e. 51 (79\%), recognized the importance of spending time with parents and/or grandparents to learn or practice Nandi proficiency. The reason they needed to be competent in the Nandi language was mainly to communicate with parents, grandparents and older people in the village. Onethird, i.e. 21 (33\%), mentioned the importance of language as a part of their culture. Only two learners (3\%) said they needed Nandi to communicate with friends. Clearly, the learners connected the Nandi language to their cultural identity and family relationships more than school instructional purposes.

\subsubsection{Kiswahili Language}

As many as 50 out of 64 learners (78\%) said they learned Kiswahili only in school, (5\%) learnt at home, while (17\%) identified both school and home as sites where they learnt Kiswahili. All except three said they began to learn Kiswahili when they began pre-school, while three had already learned Kiswahili at home before enrolling in school. When asked with whom they spoke Kiswahili, 29 (45\%) mentioned family, (34\%) spoke with friends and (20\%) with teachers, while only $13(20 \%)$ spoke Kiswahili with teachers. Most of the learners, $29(61 \%)$ said they preferred to speak Kiswahili in school, 15 (23\%) identified both school and home; three learners (5\%) spoke it at home and with friends, and seven learners (11\%) preferred to speak Kiswahili everywhere.

When the learners did not understand Kiswahili words, $26(41 \%)$ said that they would ask someone, without specifying whom; 24 (38\%) sought help from teachers, and $14(22 \%)$ said they could ask parents, friends and teachers. Regarding their rationale for learning Kiswahili, most learners, i.e. 39 (61\%), recognised its value in school-related tasks, such as in supporting them to cooperate with teachers, to pass exams and to read, write and speak the language. Nine learners (14\%) recognised it as a national language, with one learner connecting it to the national anthem. Seven learners (11\%) said that Kiswahili was the language they could speak to everyone, and eight (13\%) said this was the easiest language to use when talking with friends and classmates. When asked to identify the language that they used when they wrote SMSs to their friends (as said, this was only done in one class), only five learners out of 21 (24\%) identified Kiswahili, while 16 (76\%) identified both Kiswahili and English. No learner said Nandi.

\subsubsection{English language}

The learning of English language was also identified by the learners. While 63 (98\%) of the learners reported that they learned English at school, only one learner identified both home and school as their sites of English language 
learning; 36 learners (56\%) said they learned English when they were in standard four to six, 17 (27\%) said standard one to three and 11 (17\%) said primary school. All but two learners (97\%) said they spoke English with their teachers or teachers and classmates, while the two (3\%) said they spoke English with friends. They also said they preferred to speak English in school. Only one learner preferred to speak English at home and school.

Again, almost half of the learners (41\%) said that they could ask someone if they did not understand the language, but 31 (48\%) learners were more specific and said they could ask teachers or use dictionaries or other tools related to school. Six said they could ask both teachers and classmates, and one only asked classmates only. For learners to learn English better, 52 learners (81\%) recognised additional practice and completing activities related to school to enhance their learning. Twelve learners (19\%) said that to speak English would help them to learn the language even better. About two-thirds, i.e. 41 (64\%), said they needed English to pass exams and to learn valuable skills in school, and 19 (30\%) said it was important to learn English to communicate with other people. None mentioned the role of English in relating with family or friends, but four learners (6\%) related English to culture.

\subsubsection{The learners' opinions of their competencies in the three languages}

As explained in Section 5 on methodology, the learners were asked to scale their multilingual competence from zero to five, and the learners' opinions of their competencies in the three languages are presented in Table 3.

As Table 3 shows, there was a significant relationship between the learners' competence in understanding and speaking Nandi and in reading and writing Nandi. About 50 learners said that they understood and spoke Nandi very well, but very few said the same for reading and writing. They mostly said "bad" or even "very bad". Five (8\%) said they could not write Nandi at all.

About half of the learners said their competence in understanding and speaking Kiswahili was "good", and about a third said their competence was "very good". For reading and writing, about half of the learners said "very good". The other half of the learners had different answers for reading and writing. Most said "fair" related to reading and most said "good" related to writing.

The learners' opinions about their own competencies in understanding and speaking English was divided between "fair" and "good", but some also said "bad" and even "very bad". For reading and writing, almost all learners said "good" or "very good". 
Table 3: The learners' opinion of their multilingual competence.

\begin{tabular}{lllll}
\hline & $\begin{array}{l}\text { Competence } \\
\text { in understanding }\end{array}$ & $\begin{array}{l}\text { Competence } \\
\text { in speaking }\end{array}$ & $\begin{array}{l}\text { Competence } \\
\text { in reading }\end{array}$ & $\begin{array}{l}\text { Competence } \\
\text { in writing }\end{array}$ \\
\hline Nandi & no: 0 & no: 0 & no: 0 & no: 5 \\
& very bad: 2 & very bad: 0 & very bad: 12 & very bad: 21 \\
& bad: 1 & bad: 7 & bad: 27 & bad: 20 \\
& fair: 5 & fair: 4 & fair: 15 & fair: 11 \\
& good: 4 & good: 2 & good: 4 & good: 3 \\
& very good: 52 & very good: 51 & very good: 3 & very good: 4 \\
Kiswahili & no: 0 & no: 0 & no: 0 & no: 0 \\
& very bad: 0 & very bad: 0 & very bad: 1 & very bad: 1 \\
& bad: 1 & bad: 3 & bad: 2 & bad: 3 \\
& fair: 13 & fair: 8 & fair: 14 & fair: 4 \\
& good: 31 & good: 30 & good: 11 & good: 25 \\
& very good: 19 & very good: 23 & very good: 36 & very good: 30 \\
no: 0 & no: 0 & no: 0 & no: 0 \\
& very bad: 1 & very bad: 3 & very bad: 2 & very bad: 2 \\
bad: 10 & bad: 6 & bad: 2 & bad: 2 \\
fair: 24 & fair: 31 & fair: 6 & fair: 10 \\
good: 25 & good: 16 & good: 17 & good: 22 \\
& very good: 4 & very good: 8 & very good: 37 & very good: 28 \\
\hline
\end{tabular}

\subsection{Perceived learners' competencies in languages used in context: a summary}

Based on the data, the recommendations of the syllabus of 2002 were not implemented in these schools, even 15 years after its adaption. The schools did not offer Nandi as a subject of study, and only one school used Nandi as the MoI during the first two years of primary education. The learners in upper primary schools were even punished if they spoke the indigenous language. Even if Kiswahili is not mentioned as an MoI in the syllabus of 2002, Kiswahili was the MoI in almost all classes in all schools except upper primary in one school. In addition to upper primary education, as mentioned in the syllabus, English was also the MoI in lower primary education in two schools.

All teachers said the learners had the best competence in Kiswahili for understanding, speaking and reading. For writing, the answers were divided between Kiswahili and English. Fourteen out of 15 (93\%) teachers said the learners had good or very good abilities to express their feelings in Nandi, and 
11 said the same for Kiswahili. No teacher believed the learners could express their feelings well in English. More than half of the teachers said the learners preferred to express their feelings in Kiswahili due to the learners' competence and because this was the language most often used.

It is argued that where the learners prefer to use the language and the reasons they need to learn the languages provide important knowledge regarding how they value the languages and their multilingualism.

Figures 2 illustrate where the learners preferred to speak Nandi, Kiswahili and English. This data also summarise the assertion that Kiswahili is the preferred "between school and home" language; Nandi is the preferred language to use at home, Kiswahili is preferred to use both at home and in school and English is preferred mainly in school. The data also show (Table 3) that the learners' opinions were that they could master understanding and speaking Nandi but had difficulties reading and writing Nandi. This is perhaps because Nandi is more of an oral than a written language. In English, it was the opposite, although there were no significant differences. In Kiswahili, they mastered all skills.

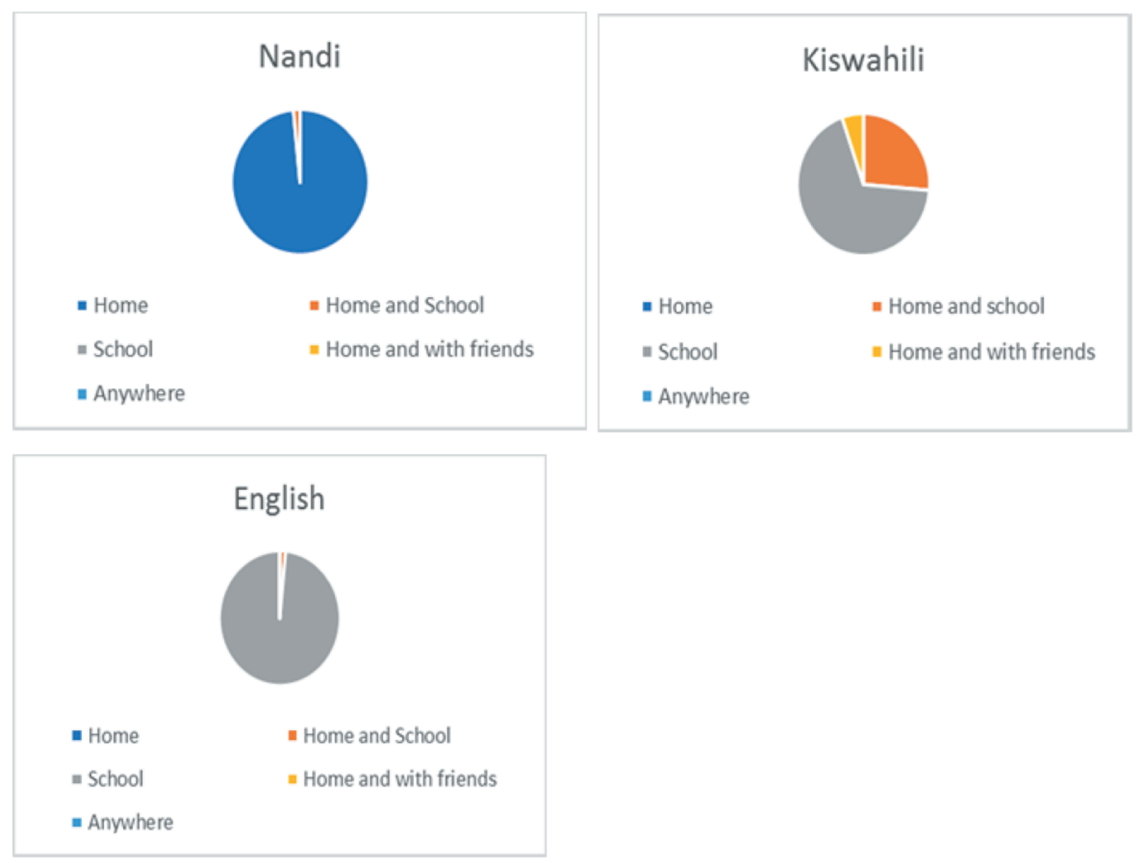

Figures 2: Where the students preferred to speak Nandi, Kiswahili and English. 


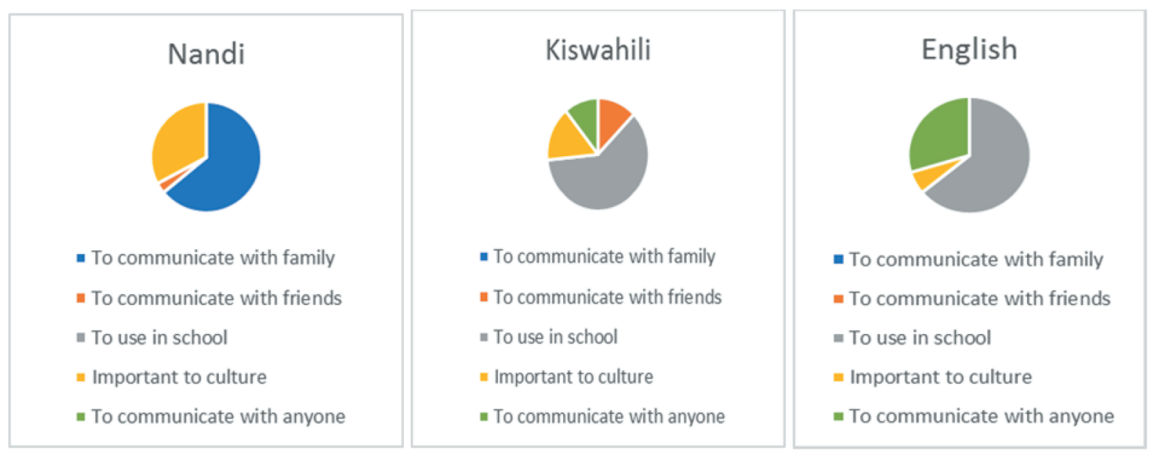

Figures 3: The learners' opinion of why they need to know the three languages.

Figures 3 indicate why the learners believed they need to know the languages Nandi, Kiswahili and English. The figures show that the learners mainly relate Nandi to communication with family and for cultural identity. As one of the learners said, "I need Nandi to help old people”. Another said, "If I don't know Nandi, I don't understand what my people are talking about”. The learners connected they need to master English to school work. One said, "English is important. When I master English, it will not be hard in secondary and university". English is also the language for communication with anyone else outside school, "I need English to understand what people are talking about." One noted English as important because of the national anthem. Again, Kiswahili is "the language between". Kiswahili is also important because of culture, and one mentioned the national anthem. They also understood the importance of Kiswahili to communicate with family and anyone else. One even said, "Many people like speaking Kiswahili, and when I speak Kiswahili I can also speak to Europeans”. However, Kiswahili is mainly important because of education, to write well, to read well, to communicate better and to understand more. As one said, "When I know Kiswahili, I can understand teachers and pupils in school”.

\section{Discussion}

As the research review shows, using the MT as the MoI is important for multilingual learners' learning outcomes (Brock-Utne and Holmarsdottir 2004; Cummins 2007; Heugh 2009; Krashen 1985; Skutnabb-Kangas 2009; Thomas and Collier 1997). However, the definition of MT is almost non-existent or is equated with indigenous languages, and thereby the research highlights indigenous languages as the 
preferred MoI in schools. Our findings also show that in standard eight, Kiswahili became the learners' spontaneous language.

The learners in this study belonged to the Nandi culture, and if the definition "acquired from birth" is used, their MT is Nandi. The Nandi language was developed through experiences as a spontaneous language as they developed (cf. Vygotsky 2012). When they began pre-primary school, they could use Nandi, but in lower primary schools, the Nandi language only had value in one school in the study. The learners understood and spoke Nandi, which was acquired through experiences, but they rarely used this experience in learning to read and write. This means they did not learn Nandi as an academic language (cf. Vygotsky 2012), but Nandi continued to be a spontaneous language. Although according to Vygotsky, Nandi was valuable for learning the other academic concepts in school (cf. Vygotsky 2012), the school did not require this competence.

While Nandi was learned as a spontaneous language, Kiswahili and English were learned in pre- and primary schools as academic languages (cf. Vygotsky 2012). Both languages were subjects of study as well as the MoI. The learners' opinions were that they had competence in writing and reading English (academic concepts) but not in speaking and understanding English (spontaneous concepts) (cf. Vygotsky 2012). In standard eight, English was still mainly an academic language rather than a spontaneous language.

For Kiswahili, the learners used the language both outside and within the school; some even spoke Kiswahili with their parents. The data show that Kiswahili was the language they mastered best. Kiswahili is mainly learned as an academic language, but because it was the preferred language when with friends, such as for SMS, it has become a spontaneous language (cf. Vygotsky 2012). Kiswahili was the language the learners spoke most often, understood best and used to explain themselves comfortably, and it was the language they preferred to use when they expressed feelings. These characterisations are the same as characterisations of an MT (cf. Lunga 2004; Omoniyi and White 2006). In standard eight, Kiswahili was identified as the language important for friendship (spontaneous concepts), school (academic concepts) and national identity (both spontaneous and academic concepts).

\section{Conclusion}

The research questions explored whether a school's implementation of the curriculum and multilingual learners' affiliations with their different languages 
could indicate which language may be preferred as the medium of instruction in schools. Based on the analysed data, both the MoI used in school, which does not adhere to the recommendations in the curriculum, and the learners' affiliations with their different languages can provide information regarding the preferred MoI in education.

The new Basic Education Curriculum Framework, 2017 (Kenya Institute of Curriculum Development 2017) in Kenyan education highlights the importance of indigenous languages and mandates that indigenous languages become subjects of study in pre-primary and primary education. In secondary education, indigenous languages become an optional subject. Kiswahili and English become subjects of study in pre-primary, primary and secondary education. The curriculum framework places little emphasis on which language(s) should be the MoI in schools. The only statements related to the MoI in education are the following: "[indigenous languages should] be used as a MoI at the early year's education level”, (p. 22), “in pre-primary education, the medium of instruction is the language of the catchment area" (p. 30) and "it [English] is the language of instruction from grade four onwards, including colleges and universities" (p. 42). The curriculum says nothing about the MoI in primary education or the first three years of secondary education. Thus, the curriculum must be more precise and should include the following successive multilingual model ${ }^{3}$ :

- Pre-primary and primary education: (1) Kiswahili and (2) the indigenous language if people in the catchment area speak an indigenous language

- Secondary education: Kiswahili and English

The reasons for a successive multilingual model in which Kiswahili is essential are:

1. When people speak an indigenous language in the catchment area, this will be the spontaneous language that is important for learning the academic language in school

2. Kiswahili has social status and is the preferred language of learners, parents, teachers and head teachers

3. Kiswahili is the national language, a language that may have a unifying effect on the Kenyan people (since independence in Africa, the various indigenous groups in the country have had conflicts [Nugent 2012]).

4. English is a world language that is important to education and international communication.

3 The new curriculum recommends a new educational system with two years of pre-primary, six years of primary and six years of secondary. 
Finally, based on the indigenous languages' importance to indigenous knowledge and cultural identity (Gandolfo 2009), the Basic Education Curriculum Framework, 2017 (Kenya Institute of Curriculum Development 2017) is recommended, which highlights indigenous languages and cultures as subjects of study in education.

Acknowledgements: We are grateful to all learners, teachers and head teachers who took part in this research, and we hope that the results of this study shall make their time worthwhile. We must also thank our multilingual research assistant, Zeddy Jepkemei, for her priceless assistance throughout data collection, transcription and translation. This research did not receive any specific grant from funding agencies in the public, commercial or not-for-profit sectors.

\section{References}

Altinyelken, Hu“lya Kosar, Sarah Moorcroft \& Hilde Van Der Draai. 2014. The dilemmas and complexities of implementing language-in-education policies: Perspectives from urban and rural contexts in Uganda. International Journal of Educational Development 36. 90-99. https://www.sciencedirect.com/science/article/pii/S0738059313000837.

Brock-Utne, Birgit. 1997. The language question in Namibian schools. International Review of Education 43(2). 241-260. https://link.springer.com/article/10.1023/A:1002933418640.

Brock-Utne, Birgit. 2007. Learning through a familiar language versus learning through a foreign language-A look into some secondary school classrooms in Tanzania. International Journal of Educational Development 27. 487-498. https://www.sciencedir ect.com/science/article/pii/S0738059306001234.

Brock-Utne, Birgit \& Halla B. Holmarsdottir. 2004. Language policies and practices in Tanzania and South Africa: Problems and challenges. International Journal of Educational Development 24(1). 67-83. https://www.sciencedirect.com/science/article/pii/ S0738059303001159.

Creswell, John W. 2012. Educational Research. Planning, conducting, and evaluating quantitative and qualitative research, 4th edn. Boston: Pearson International Edition.

Cummins, Jim. 2007. Rethinking monolingual instructional strategies in multilingual classrooms. Canadian Journal of Applied Linguistics 10(2). 221-240. https://journals.lib.unb. ca/index.php/CJAL/article/view/19743.

Gandolfo, Andrew J. 2009. Education-medium and African linguistic rights in the context of globalisation. Globalisation, Societies and Education 7(3). 321-336. http://www.tandfon line.com/doi/abs/10.1080/14767720903166129.

Githiora, Chege. 2008. Kenya: Language and the search for a coherent national identity. In A. Simpson (eds.), Language \& national identity, 235-251. Oxford: Oxford University Press.

Heugh, Kathleen. 2009. Contesting the monolingual practices of a bilingual to multilingual policy. English Teaching: Practice and Critique 8(2). 96-113. https://search.proquest.com/ openview/fbe193cb7d90cff96a9b9470f046ad61/1?pq-origsite $=$ gscholar\&cbl = 736343 . 
Heugh, Kathleen, Carol Benson, Berhanu Bogale \& Meconnen Alemu Gebre Yohannes. 2007. Final Report Study on Medium of Instruction in Primary Schools in Ethiopia. Ministry of Education, Ethiopia.

Kenya Institute of Curriculum Development. 2017. Basic Education Curriculum Framework, 2017. http://www.kicd.ac.ke/images/downloads/CURRICULUMFRAMEWORKFINAL2017.pdf

Kenya Institute of Education. 2002. Primary Education Syllabus. Volume One. Kenya: Ministry of Education, Science and Technology.

Kozulin, Alex. 2012. Forward. In L. Vygotsky ed., Though and language. Cambridge: MIT Press. Krashen, Stephen D. 1985. Input in second language acquisition. Oxford: Pergamon Press.

Lunga, Violet Bridget (2004). Mapping African postcoloniality: Linguistic and cultural spaces of hybridity. Perspectives on Global Development and Technology, 3(4), 291-326.

Miles, Matthew B. \& A. Michael Huberman. 1994. Qualitative data analysis: An expanded sourcebook. Thousand Oaks, CA: Sage.

Muthwii, Margaret Jepkirui. 2004. Language of instruction: A qualitative analysis of the perceptions of parents, pupils and teachers among the Kalenjin in Kenya. Language, Culture and Curriculum 17(1). 15-32. http://www.tandfonline.com/doi/abs/10.1080/ 07908310408666679.

Ngware, Moses W., Moses Oketch \& Maurice Mutisya. 2014. Does teaching style explain differences in learner achievement in low and high performing schools in Kenya? International Journal of Educational Development 36. 3-12. https://www.sciencedirect. com/science/article/pii/S073805931400008X.

Nugent, Paul. 2012. Africa since independence. London: Palgrave Macmillan.

Omoniyi, Tope \& Goodith White. 2006. Introduction. In Tope Omoniyi \& Goodith White (eds.), The sociolinguistics of identity, 1-8. London: Continuum.

Opoku-Amankwa, Kwasi. 2009. English-only language-in-education policy in multilingual classrooms in Ghana. Language, Culture and Curriculum 22(2). 121-135. http://www. tandfonline.com/doi/abs/10.1080/07908310903075159.

Puja, Grace K. 2003. Kiswahili and higher education in Tanzania: Reflections based on a sociological study from the University of Dar es Salaam. In Birgit Brock-Utne, Zubeida Desai \& Martha Qorro (eds.), Language of instruction in Tanzania and South Africa (LOITASA). Dar es Salaam: E \& D Publishers.

Ryan, Gery W. \& Russell Bernard. 2003. Techniques to identify themes. Field Method 15(1). 85-109. http://journals.sagepub.com/doi/abs/10.1177/1525822X02239569.

Shiza, Edward. 2005. Reclaiming our memories: The education dilemma in postcolonial African school curricula. In Ali A. Abdi \& Ailie Cleghorn (eds.), Issues in African education Sociological perspectives, 65-84. New York, NY: Palgrave Macmillan.

Skutnabb-Kangas, Tove. 2009. What can TESOL do in order not to participate in crimes against humanity? TESOL Quarterly: A Journal for Teachers of English to Speakers of Other Languages and of Standard English as a Second Dialect 43(2). 340-344. doi:10.1002/j.1545-7249.2009.tb00176.x.

Spernes, Kari. 2011. 'I buy paraffin so he can read in the evening' - A study from Kenya about parental involvement in school. International Journal about Parents in Education 5(1). 24-35. http://www.ernape.net/ejournal/index.php/IJPE/article/viewFile/113/73.

Spernes, Kari. 2012. 'I use my MT at home and with friends - not in school!' Multilingualism and identity in rural Kenya. Language, Culture and Curriculum 25(2). 189-203. http://www.tandfonline.com/doi/abs/10.1080/07908318.2012.683531.

Stake, Robert E. 1995. The art of case study research. Thousand Oaks, CA: Sage. 
Tchindjang, Mesmin, Athanase Bopda \& AngelíneNgamgne. Louise. 2008. Languages and cultural identities in Africa. Museum International 60(3). 37-50. http://onlinelibrary.wiley. com/doi/10.1111/j.1468-0033.2008.00651.x/full.

Thomas, Wayne P. \& Virginia Collier. 1997. School effectiveness for language minority learners. National Clearinghouse for Bilingual Education, Resource Collection Series 9. 1-97. https://eric.ed.gov/?id = ED436087.

Trudell, Barbara. 2005. Language choice, education and community identity. International Journal of Educational Development 25. 237-251. https://www.sciencedirect.com/science/ article/pii/S0738059304001075.

Trudell, Barbara. 2007. Local community perspectives and language of education in subSaharan African communities. International Journal of Educational Development 27. 552-563. https://www.sciencedirect.com/science/article/pii/S0738059307000156.

Uwezo. 2016. Are Our Children Learning? Uwezo Kenya Sixth Learning Assessment Report. Nairobi: Twaweza East Africa.

Vygotsky, Lev. 2012/1934. Thought and language. Cambridge: MIT Press.

Yin, Robert K. 2003. Case study research: Design and methods, 3rd edn. Thousand Oaks, CA: Sage. 